\title{
Monocyte Procoagulant Activity in Glomerulonephritis Associated with Systemic Lupus Erythematosus
}

\author{
E. H. Cole, J. Schulman, M. Urowitz, E. Keystone, C. Williams, and G. A. Levy \\ Department of Medicine, Wellesley Hospital, University of Toronto, Toronto, Ontario, Canada; Department of Medicine, \\ Sunnybrook Medical Centre, University of Toronto, Toronto, Ontario, Canada
}

\begin{abstract}
Monocyte infiltration and activation of the coagulation system have been implicated in the pathophysiology of glomerulonephritis. In this study, spontaneous procoagulant activity (PCA) was measured in circulating mononuclear cells to determine whether elevated PCA correlated with the presence of proliferative glomerulonephritis in patients with systemic lupus erythematosus (SLE). No increase in PCA was found in 20 patients with end-stage renal failure, 8 patients with glomerulonephritis without SLE, and 10 patients undergoing abdominal surgical or orthopedic procedures as compared with 20 normal controls. In eight patients with SLE but with no apparent active renal disease, PCA was not elevated above normal basal levels. Seven additional patients with SLE who had only mesangial proliferation on biopsy also had no increase in PCA. In contrast, eight patients with focal or diffuse proliferative lupus nephritis, and one patient with membranous nephritis who ultimately developed a proliferative lesion, had a marked increase in PCA with $>100$ times the base-line levels. The activity was shown to originate in the monocyte fraction of the mononuclear cells and was shown to be capable of cleaving prothrombin directly. The prothrombinase activity was not Factor $\mathrm{Xa}$, because it was not neutralized by anti-Factor $X$ serum and was not inhibited by an established panel of Factor $\mathrm{Xa}$ inhibitors. Monocyte plasminogen activator determinations did not correlate with renal disease activity. We conclude that monocyte procoagulant activity, a direct prothrombinase, seems to correlate with endocapillary proliferation in lupus nephritis and could be a mediator of tissue injury.
\end{abstract}

\section{Introduction}

Morbidity and mortality in patients with systemic lupus erythematosus (SLE) ${ }^{1}$ have been shown to correlate with renal pathology $(1,2)$. Therefore, to optimize therapy and determine prognosis, an accurate assessment of renal disease is important.

Dr. Levy is the recipient of a Medical Research Council of Canada Scholarship.

Address reprint requests to Dr. E. Cole, St. Michael's Hospital, 30 Bond St., Toronto, Ontario, Canada M5B 1W8.

Received for publication 29 May 1984 and in revised form 20 September 1984.

1. Abbreviations used in this paper: DFP, diisopropylfluorophosphate; GN, glomerulonephritis; LPS, lipopolysaccharide (endotoxin); PA, plasminogen activator; PAGE, polyacrylamide gel electrophoresis; PBM, purified blood mononuclear cells; PCA, procoagulant activity; PMSF, phenylmethylsulfonyl fluoride; PTT, partial thromboplastin time; SLE, systemic lupus erythematosus.

J. Clin. Invest.

(C) The American Society for Clinical Investigation, Inc.

0021-9738/85/03/861/08 $\$ 1.00$

Volume 75, March 1985, 861-868
Clinical assessment, lupus serology, serum complement levels, serum immune complex levels, and renal function have shown good correlation with disease activity in several groups of patients with SLE (3-5) but are often not useful in the assessment of disease activity in individual patients suggesting other factors may be important in pathogenesis and activity.

A number of recent studies have demonstrated that macrophages are important mediators of injury in some forms of glomerulonephritis. Several studies suggest that proliferating cells within the glomerulus are derived from circulating monocytes as well as intrinsic glomerular cells $(6,7)$. Holdsworth et al. (8), in experimental glomerulonephritis in the rabbit, have shown that macrophages are present during the development of injury and that depletion with a specific anti-macrophage serum was able to abrogate glomerular injury. In a number of studies, the importance of the coagulation system in the pathogenesis of glomerulonephritis has been demonstrated.

In both human and animal models of crescentic glomerulonephritis, fibrin and platelets are present in Bowman's space; and in experimental models, the appearance of fibrin precedes the development of crescents (9). Anticoagulation with heparin prevents injury in experimental nephritis and possibly in human disease $(10,11)$. Defibrination with ancrod prevents the appearance of fibrin in the urinary space, and the development of crescents, and significantly lessens renal injury in nephrotoxic nephritis in rabbits (9). Activation of the coagulation system and thrombosis have been noted in SLE, and recent data also suggest a therapeutic role for ancrod in patients with SLE and glomerulonephritis $(12,13)$.

It has been known for a long time that lymphoid cells express procoagulant activity after stimulation both in vitro and in vivo (14). The cellular source of this activity is the monocyte/macrophage, but $T$ cells are necessary for the induction of these procoagulant monokines (15). At least three procoagulant monokines have been defined in human mononuclear cells. First, the induction of thromboplastin (tissue factor) has been described in response to lipopolysaccharide (endotoxin; LPS) and lectins (concanavalin A and phytohemmaglutinin). Second, a Factor $\mathrm{X}$ activating factor produced by monocyte/macrophages has been demonstrated in response to tumors. Finally, a direct prothrombin activating factor (prothrombinase) that is unrelated to Factor $\mathrm{Xa}$ has been documented in response to specific lipoproteins and viral infection (16).

In this report, we describe the spontaneous expression of monocyte procoagulant activity (PCA) by mononuclear cells, which directly correlated with endocapillary proliferation in patients with lupus nephritis.

\section{Methods}

Renal pathology. Renal biopsies were performed by the percutaneous or open wedge technique, and handled and processed in a standard manner. Specimens for histologic study were embedded in paraffin and sections were stained with hematoxylin and eosin, periodic acid- 
Schiff, and periodic acid-silver methionine. Tissue for immunofluorescence was snap frozen, sectioned, and stained with fluorescein isothiocyanate conjugated monospecific antisera against IgG, IgA, IgM, third component of human complement (C3), and fibrinogen (Cappel Laboratories, Cochranville, PA).

Tissue for electron microscopy was fixed in osmium tetroxide before mounting and viewing.

Pathologic diagnosis was made according to World Health Organization criteria (17).

Cell isolation. Peripheral blood mononuclear cells were isolated from the heparinized peripheral blood of normal controls and patients by centrifugation over Ficoll-Hypaque at $1,400 \mathrm{~g}$ at $22^{\circ} \mathrm{C}$ for $12 \mathrm{~min}$. The cells were adjusted to $1 \times 10^{6} / \mathrm{ml}$, and lymphocytes and monocytes were separated by adherence to fibronectin-coated plastic flat bottom 16-mm diam, 24-well plates (Flow Laboratories, McLean, VA) in 1$\mathrm{ml}$ vol in complete medium (Dulbecco's modified essential medium containing $10 \%$ fetal calf serum, $25 \mu \mathrm{g} / \mathrm{ml}$ aureomycin, grade II (Sigma Chemical Co., St. Louis, MO). After a 60-min incubation, the nonadherent cells were washed free from the plate. The adherent cells were recovered by incubation at $4^{\circ} \mathrm{C}$ for $20 \mathrm{~min}$ with a solution containing $3 \mathrm{mM}$ ethylene diaminetetraacetic acid. The recovery of cells was $>84 \%$ and viability was $>95 \%$ as demonstrated by trypan blue exclusion. Lymphocytes were defined by the failure of adherence, morphology, and failure of uptake of neutral red, and were $<1 \%$ esterase positive. Monocytes were defined by morphology, uptake of neutral red, and were $>96 \%$ esterase positive as previously described (15).

$P C A$. Samples of viable cells or frozen-thawed and sonicated cells were assayed for the capacity to shorten the spontaneous clotting time of human plasma in a one stage clotting assay. The total cellular content of PCA was determined in a one-stage clotting assay as described previously. Purified blood mononuclear cells (PBM), monocytes, and lymphocytes at $1 \times 10^{6} / \mathrm{ml}$ in $12 \times 75 \mathrm{~mm}$ polypropylene tubes (Falcon Plastics, Oxnard, CA) were subjected to three cycles of freeze-thaw and sonication. To $0.1 \mathrm{ml}$ of the cellular homogenate at $37^{\circ} \mathrm{C}$ was added $0.1 \mathrm{ml}$ of citrated normal human platelet poor plasma or factor deficient plasma (Helena Laboratories, Beaumont, TX) and $0.1 \mathrm{ml}$ of $25 \mathrm{mM} \mathrm{CaCl}_{2}$ was added to start the reaction. The time in seconds for the appearance of a fibrin gel was recorded. To establish units, a rabbit brain thromboplastin standard at $36 \mathrm{mg}$ dry mass per milliliter (American Dade Div., American Hospital Supply Corp., Miami, FL) was assigned a value of $100,000 \mathrm{mU}$. The assay was used over the range of $1-100,000 \mathrm{mU}$ or $10^{2}$ to $10^{8}$ cells, and the results were linear with normal plasma substrate. The precision (coefficient of variation) of assays was $9.1 \%$ at the lower limit and $5.9 \%$ at the upper limit. Data was expressed as the mean and standard deviation of triplicate assays. Media with or without $10 \%$ fetal calf serum and buffers were all without activity (15).

Endotoxin contamination. All media and buffers were assayed for endotoxin contamination by a standard limulus assay (E. Toxate; Sigma Chemical Co., St. Louis, MO) and contained $<0.1 \mathrm{ng}$ per milliliter of endotoxin, the lower limits of the assay.

Assay of direct prothrombin cleavage. Factor $\mathrm{X}$ and prothrombin were isolated from Cohn fraction III as previously described (18). For assay of cleavage, prothrombin was radioiodinated enzymatically with immobilized lactoperoxidase and glucose oxidase (Enzymobeads; BioRad Laboratories, Richmond, CA) to a specific activity of $6.2 \mu \mathrm{Ci} / \mu \mathrm{g}$. To $25 \mu$ l of cellular homogenates of PBM from patients or control subjects was added $10 \mu \mathrm{l}$ of ${ }^{125} \mathrm{I}$-prothrombin and $10 \mu \mathrm{l}$ of $25 \mathrm{mM}$ $\mathrm{CaCl}_{2}$. The reaction was allowed to proceed at $37^{\circ} \mathrm{C}$ for $30 \mathrm{~min}$. Human Factor $\mathrm{Xa}(0.5 \mu \mathrm{g} / \mathrm{ml})$ in the presence of homogenates of $10^{6}$ unstimulated cells was used as a positive control for ${ }^{125} \mathrm{I}$-prothrombin cleavage. Each reaction mixture was assayed for prothrombin cleavage on $0.1 \%$ sodium dodecyl sulfate (SDS), $10 \%$ polyacrylamide slab gels prepared according to Laemmli (19). Following electrophoresis, the gels were fixed, dried, and analyzed by autoradiography for ${ }^{125} I$ prothrombin and its cleavage products. Assessment of susceptibility of PCA from patients with SLE to protease inhibitors was performed as described previously (18). Cell homogenates $(50 \mu \mathrm{l})$ were incubated with antithrombin III $(10 \mu \mathrm{l} / \mathrm{ml})$ in the presence or absence of heparin $(1 \mathrm{U} / \mathrm{ml})$, trasylol $(10 \mathrm{U} / \mathrm{ml})$, soybean trypsin inhibitor $(10 \mu \mathrm{l} / \mathrm{ml})$, benzamidine (1 mM), phenylmethylsulfonyl fluoride (PMSF; $1 \mathrm{mM}$ ), or diisopropylfluorophosphate (DFP; 2.5 and $10 \mathrm{mM}$ ). After a 5-min incubation with inhibitor at $22^{\circ} \mathrm{C}, 10 \mu \mathrm{l}$ of ${ }^{125} \mathrm{I}$-prothrombin and 10 $\mu \mathrm{l}$ of $25 \mathrm{mM} \mathrm{CaCl}$ were added and the reaction mixture incubated an additional $30 \mathrm{~min}$ at $37^{\circ} \mathrm{C}$. ${ }^{125} \mathrm{I}$-prothrombin cleavage was then assessed by SDS-polyacrylamide gel electrophoresis (PAGE) and autoradiography. Human Factor $\mathrm{Xa}(0.5 \mu \mathrm{g} / \mathrm{ml})$ in the presence of homogenates of unstimulated control cells was treated identically for comparison.

Antibody neutralization of PCA was examined using rabbit antisera to human Factor $\mathrm{X}$ as previously described (18). Human Factor Xa in the presence of control homogenates of $10^{6} \mathrm{PBM}$ or homogenates from patients with SLE and other renal diseases was added to rabbit anti-Factor $\mathrm{X}$ immune serum. Aliquots were removed, and after a 6-h incubation at $22^{\circ} \mathrm{C}$, were combined with ${ }^{125} \mathrm{I}$-prothrombin and $\mathrm{CaCl}_{2}$ at $37^{\circ} \mathrm{C}$ for $30 \mathrm{~min}$ and analyzed following SDS-PAGE and autoradiography.

Plasminogen activator. Plasminogen was isolated from citrated normal human fresh frozen plasma according to a modification of the method of Deutsch and Mertz (20). 70 IU ancrod (Connaught Laboratories, Ltd., Willowdale, Ontario, Canada) was added to each liter of plasma and the plasma was stirred gently overnight at $4^{\circ} \mathrm{C}$. After filtration, the plasma was diluted 1:1 with $0.1 \mathrm{M} \mathrm{PO}_{4}, \mathrm{pH} 7.4$, containing $3 \mathrm{mM}$ EDTA and $2 \mathrm{mM}$ PMSF. The solution was loaded onto a Sepharose-Lysine column, the column washed with $\mathrm{PO}_{4}$ buffer pH 7.4 containing $3 \mathrm{mM}$ EDTA and $2 \mathrm{mM}$ PMSF until the optical density at $280 \mathrm{nM}$ was $<0.01$, and the plasminogen was then eluted off of the column with $0.2 \mathrm{M}$ epsilon amino caproic acid in $0.3 \mathrm{M}$ $\mathrm{PO}_{4}$ containing $3 \mathrm{mM}$ EDTA and $2 \mathrm{mM}$ PMSF. The plasminogen

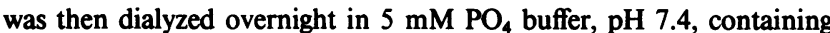
$2 \mathrm{mM}$ PMSF with frequent changes. The plasminogen was then

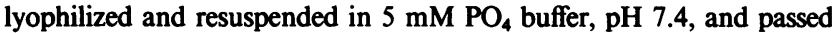
through a Sephadex column. The protein peak was recovered and dialyzed against $0.1 \mathrm{M}$ Tris buffered saline at $4^{\circ} \mathrm{C}$. Protein concentration was determined in a standard Lowry assay, and plasminogen was stored in aliquots at $-70^{\circ} \mathrm{C}$ until use.

Fibrinogen (Kabi; Sigma Chemical Co., St. Louis, MO) was radioiodinated enzymatically with immobilized lactoperoxidase and glucose oxidase and diluted with cold fibrinogen. Plastic flat-bottom 16-mM diam 24-well plates (Linbro Plastics, McLean, VA) were then coated with the fibrinogen and dried at room temperature for $3 \mathrm{~d}$. Fibrinogen was then converted to fibrin by adding acid treated fetal calf serum as a source of thrombin to each well for $4 \mathrm{~h}$ at $37^{\circ} \mathrm{C}$. To each well, $1 \mathrm{ml}$ of $0.1 \%$ gelatin in Tris buffered saline was added, which contained 10 $\mu \mathrm{g}$ of plasminogen and an aliquot of cellular homogenate from control patients, patients with SLE, streptokinase (Sigma Chemical Co., St. Louis, MO), or plasmin as positive controls. After a 45-min incubation at $37^{\circ} \mathrm{C}$, the supernatants were removed and counted in a gamma counter. Results are expressed as the mean of triplicate samples of percent of maximum ${ }^{125}$ I released per $10^{6}$ monocytes as compared with cpm released by the plasmin control.

\section{Results}

Patient profiles. 24 patients with SLE were studied through the Rheumatic Disease Unit of the Wellesley Hospital. All patients met at least four American Rheumatism Association criteria for the diagnosis of SLE. Patients were evaluated for organ systems involved, serology, serum complement levels, and therapy at the time of the study (Table I). All patients were seropositive (Table I) at the time of diagnosis, and 18 remained positive at the time of the study. 11 of the patients had normal serum complement levels. 20 patients had skin lesions, 15 had arthritis, 6 had Raynaud's phenomenon, 3 had serositis, 9 had central nervous system involvement, and 5 had 
Table I. Clinical Profiles of Patients in Study

\begin{tabular}{|c|c|c|c|c|}
\hline Patient no. & Serology* & $\begin{array}{l}\text { Serum } \\
\text { complement }\end{array}$ & Extrarenal involvement & Therapy \\
\hline \multicolumn{5}{|l|}{ Group 1} \\
\hline 1 & + & $\mathbf{N}$ & Skin, CNS & P (30 mg) \\
\hline 2 & + & D & Vasculitis, joints & $P(15 \mathrm{mg})$ \\
\hline 3 & + & $\mathbf{N}$ & Joints & Salic \\
\hline 4 & - & $\mathbf{N}$ & Skin, joints & None \\
\hline 5 & + & $\mathrm{N}$ & Haem, joints, skin & Chlor, NSAI \\
\hline 6 & + & $\mathrm{D}$ & Skin, joints & Chlor, salic \\
\hline 7 & + & D & Skin, joints & None \\
\hline \multicolumn{5}{|l|}{ Group 2} \\
\hline 8 & + & D & Skin, joints, Raynaud's & Chlor \\
\hline 9 & + & $\mathrm{N}$ & Skin, serositis, lymphad & P (22.5 mg)Alt \\
\hline 10 & + & D & Skin, joints, Raynaud's & None \\
\hline 11 & + & $\mathrm{D}$ & Skin, joints, CNS & $P(40 \mathrm{mg})$ \\
\hline 12 & - & $\mathbf{N}$ & Skin, CNS & $P(100 \mathrm{mg})$ \\
\hline 13 & + & D & $\begin{array}{l}\text { Skin, joints, serositis } \\
\text { Vasculitis }\end{array}$ & None \\
\hline 14 & + & $\mathrm{D}$ & Skin, CNS, vasculitis & $P(60 \mathrm{mg})$ \\
\hline 15 & + & $\mathbf{N}$ & Skin, joints, vasculitis, CNS & $P(100 \mathrm{mg})$ \\
\hline 16 & + & D & Skin, joints, eye & $\mathrm{P}(12.5 \mathrm{mg})$ \\
\hline \multicolumn{5}{|l|}{ Group 3} \\
\hline 17 & - & $\mathbf{N}$ & Nil & $\mathrm{P}(7.5 \mathrm{mg})$ \\
\hline 18 & + & D & Serositis, skin, Raynaud's & $P(20 \mathrm{mg})$ \\
\hline 19 & + & $\mathbf{N}$ & Skin, joints, Raynaud's & P (30 mg), Im \\
\hline 20 & - & $\mathbf{N}$ & Skin, CNS, haem & $P(60 \mathrm{mg}), \mathrm{Im}$ \\
\hline 21 & + & D & Joints, CNS, haem & $P(100 \mathrm{mg})$ \\
\hline 22 & + & D & Skin, joints, Raynaud's & Chlor \\
\hline 23 & - & $\mathbf{N}$ & Skin, CNS, Raynaud's & P (20 mg) \\
\hline 24 & - & $\mathrm{D}$ & Skin, CNS & $P(40 \mathrm{mg})$ \\
\hline
\end{tabular}

N, normal; D, decreased. Chlor, chloroquine; CNS, central nervous system; haem, haematologic; Im, Imuran; NSAI, nonsteroidal anti-inflammatory; P, prednisone per day; salic, salicylates. ${ }^{*}(+)$, Positive serology, indicates that any of antinuclear factor, lupus erythematosus cells, and/or anti-DNA antibody are present. (-), Negative serology, refers to the absence of antinuclear factor, lupus erythematosus cells, or antiDNA antibody.

frank vasculitis. 15 of the patients were receiving prednisone, 2 patients were receiving azothiaprine (imuran), and the remainder received salicylates, chloroquine, or nonsteroidal antiinflammatory agents. 3 patients were on no therapy at the time of the study (Table I).

Coagulation parameters were studied in all patients before entry into the study. These included partial thromboplastin time (PTT), prothrombin time, and platelet count. PTT was within normal limits in all patients except for patient 10 , in which the PTT was below normal values. The prothrombin time was normal in all patients except for patient 21 , who was on coumadin at the time of the study because of previous consumptive coagulopathy. Four patients had mild thrombocytopenia (Table II). No thrombotic episodes were seen in any patient at the time of this study except for patient 14 , who had renal vein thrombosis and who was treated with coumadin after completion of the study.

Spontaneous expression of PCA. The surface expression of PCA by suspensions of viable PBM as well as the total content PCA contained in lysed cell suspensions was determined. Since renal failure was likely to coexist in some patients with lupus nephritis, the effect of renal failure on PCA was studied in 20 patients with stable end-stage renal failure who were receiving regular dialysis, and this was compared with 20 normal controls. Of the patients with end-stage renal failure, 12 were on hemodialysis and 8 were on peritoneal dialysis. Since surgery has been reported to be associated with a hypercoagulable state, 10 patients were studied before and after abdominal or orthopedic procedures. Additionally, eight patients with heavy proteinuria and glomerulonephritis without SLE were studied. Five of these patients had minimal lesion glomerulonephritis, one had idiopathic membranous glomerulonephritis, and two had idiopathic mesangial proliferative glomerulonephritis. Both viable and total content PCA were equivalent in all of these patient groups (Table III). Viable PCA was $25 \%$ of total content PCA. Monocytes were the cellular source of $>92 \%$ of both the viable and total content PCA as determined by assaying purified cell populations (data not shown).

Monocyte PCA, renal function, and pathology in patients with SLE. In the 24 patients with SLE studied, microscopic urinalysis, creatinine clearance, 24-h urinary protein, and concurrent renal biopsy where available were compared with monocyte/macrophage total content PCA. Clinical and laboratory assessments were performed independently and each 
Table II. Coagulation Parameters of Patients in Study

\begin{tabular}{|c|c|c|c|}
\hline Patient no. & $\begin{array}{l}\text { Platelets* } \\
\left(\times 10^{-3}\right)\end{array}$ & $\begin{array}{l}\text { Prothrombin } \\
\text { timeł }\end{array}$ & $\begin{array}{l}\text { Partial thromboplastin } \\
\text { time§ }\end{array}$ \\
\hline & & $s$ & $s$ \\
\hline 1 & 280 & 10.5 & 29 \\
\hline 2 & 207 & 10.0 & 32 \\
\hline 3 & 133 & 10.0 & 27 \\
\hline 4 & 200 & 10.5 & 32 \\
\hline 5 & 172 & 10.5 & 29 \\
\hline 6 & 360 & 12.5 & 39 \\
\hline 7 & 85 & 13.0 & 38 \\
\hline 8 & 280 & 10.0 & 33 \\
\hline 9 & 395 & 10.5 & 29 \\
\hline 10 & 225 & 10.0 & 22 \\
\hline 11 & 413 & 10.5 & 29 \\
\hline 12 & 106 & 10.0 & 36 \\
\hline 13 & 170 & 11.0 & 33 \\
\hline 14 & 116 & 10.0 & 27 \\
\hline 15 & 321 & 10.9 & 25 \\
\hline 16 & 193 & 9.5 & 26 \\
\hline 17 & 244 & 10.5 & 29 \\
\hline 18 & 275 & 11.0 & 37 \\
\hline 19 & 272 & 10.0 & 28 \\
\hline 20 & 167 & 10.0 & 26 \\
\hline 21 & 257 & 21.0 & 29 \\
\hline 22 & 230 & 10.5 & 29 \\
\hline 23 & 270 & 10.5 & 31 \\
\hline 24 & 260 & 11.0 & 29 \\
\hline
\end{tabular}

* Normal platelet count, $150,000-400,000$ per cubic millimeter. $\ddagger$ Normal prothrombin time, $10-12 \mathrm{~s}$.

$\S$ Normal partial thromboplastin time, 25-38 s.

group of investigators was not aware of the results of the other until after the study had been completed.

The patients were divided into three groups on the basis

Table III. Base-line Monocyte Procoagulant Activity

\begin{tabular}{|c|c|c|c|}
\hline \multirow[b]{2}{*}{ Patient population } & \multirow[b]{2}{*}{ No. } & \multicolumn{2}{|c|}{ Procoagulant activity* } \\
\hline & & Viable & $\begin{array}{l}\text { Total } \\
\text { content }\end{array}$ \\
\hline & & $\begin{array}{l}m U / 10^{6} \\
\text { monocytes }\end{array}$ & $\begin{array}{l}m U / 10^{6} \\
\text { monocytes }\end{array}$ \\
\hline Normal & 20 & $1.5 \pm 0.5$ & $6 \pm 2$ \\
\hline Endstage renal failure & 20 & $1.3 \pm 0.5$ & $6 \pm 1$ \\
\hline Pre-operative & 10 & $1.1 \pm 0.2$ & $4 \pm 1$ \\
\hline Post-operative & 10 & $1.0 \pm 0.1$ & $5 \pm 1$ \\
\hline \multicolumn{4}{|l|}{ Minimal lesion } \\
\hline glomerulonephritisł & 5 & $2.5 \pm 1.0$ & $5 \pm 2$ \\
\hline \multicolumn{4}{|l|}{ Membranous } \\
\hline glomerulonephritis§ & 1 & $1.3 \pm 0.5$ & $5 \pm 1$ \\
\hline \multicolumn{4}{|l|}{ Mesangial proliferative } \\
\hline glomerulonephritis" & 2 & $1.0 \pm 0.3$ & $4 \pm 1$ \\
\hline
\end{tabular}

* Spontaneous PCA measured in a one-stage clotting assay.

¥ All patients had the nephrotic syndrome (urinary protein $>3 \mathrm{~g} / \mathrm{d}$ ).

$\S$ Patient had proteinuria $(2 \mathrm{~g} / \mathrm{d})$.

"Patients had proteinuria of 1.5 and $2 \mathrm{~g} / \mathrm{d}$. of renal biopsy: group 1, 2, and 3. In group 1, there were seven patients (Table IV). All of these patients had renal biopsies within several days of the PCA determinations. Renal pathology in all of the cases showed mesangial disease except for patient 7, who also had severe interstitial fibrosis. The urine sediment in these patients varied, but heme granular casts were seen only in patient 7 . Urinary protein was abnormal in four of the patients studied, but none had heavy proteinuria. Creatinine clearance was within the normal range in all patients except patient 7. PCA determinations were also found to be at low basal levels in all of the patients in this group.

All of the patients in group 2 had renal biopsies within several days of assessment of PCA (Table V). Patients 8 and 9 both had abnormal urinalyses, normal creatinine clearance, mild to moderate proteinuria, and focal proliferative glomerulonephritis with necrosis on renal biopsy. Patients 10-15 all had diffuse proliferative glomerulonephritis, and in addition, patient 14 had venogram-proven renal vein thrombosis. All patients in this group had active lesions as evidenced by the presence of one or more of capillary thrombi, necrosis, karyorrhexis, and crescents in addition to cellular proliferation. Patient 12 had a mixture of cellular proliferation and sclerosis. Extrarenal manifestations were quite variable in these patients.

In all of the patients studied, there was a marked elevation in monocyte PCA from 800 to $2,950 \mathrm{mU} / 10^{6}$ monocytes, a 100 -fold increase over basal levels. It is noteworthy that patient 15 had no clinical or laboratory evidence of abnormal renal function, and the evidence in patients 18 and 19 was rather slight, with minimal proteinuria and slight microscopic haematuria. Patient 16 did have membranous glomerulonephritis at the time of this biopsy, but also had diffuse immunoglobulin deposition within the kidney, not only within the glomeruli, but also around the tubules and within the renal vessels as shown by immunofluorescence. This patient subsequently developed a proliferative lesion as seen on a second biopsy. Immunofluorescence was available in eight patients and fibrin could only be demonstrated in two.

The PCA assay was repeated in four patients $(10,11,13$, and 15) several months after the initial determinations, without the availability of concurrent renal biopsies but after treatmentinduced stabilization of disease as far as could be assessed by clinical means (Table VI). Repeat renal biopsies could not be performed for ethical reasons. In all of these cases, the PCA returned to normal values with apparent remission of disease (Table VI). Group 3 was composed of eight patients, none of whom had a recent renal biopsy (Table VII). Most of these patients had extrarenal manifestations of their disease, which varied from mild to severe. Patient 17 had clinically quiescent SLE, end-stage renal failure, and was clinically well on hemodialysis. Patients 18 and 19 had biopsy-proven diffuse proliferative glomerulonephritis $\sim 2$ yr before this study. Both patients had stable renal function over this time, although their extrarenal disease was active at the time of assessment. They were designated inactive with respect to their renal disease in this study. The remaining five patients in this group did not have renal biopsies. The urinary sediment was normal in patients $19,22,23$, and 24 . The creatinine clearance was normal in all patients, and proteinuria was present in three of the patients. Monocyte PCA was at basal levels in all of the patients in this group (Table VII).

Nature of PCA. Deficient plasmas were used to determine the dependence of specific factors for the full expression of 
Table IV. Spontaneous Monocyte Procoagulant Activity in Patients in Group I

\begin{tabular}{|c|c|c|c|c|c|c|}
\hline Patient no. & Microscopic urinalysis & Creatinine clearance* & Urine protein & Renal pathology & PCA $\ddagger$ & PA§ \\
\hline & & $\mathrm{ml} / \mathrm{min}$ & $g / 24 h$ & & & \\
\hline 1 & Normal & 109 & Negative & Mesangial & 5 & 19 \\
\hline 2 & 4-8 leukocytes & 107 & 0.1 & Mesangial & 3 & - \\
\hline 3 & Normal & 110 & Negative & Mesangial & 2 & - \\
\hline 4 & 4-6 leukocytes & 110 & 0.58 & Mesangial & 5 & - \\
\hline 5 & 10-15 leukocytes & 120 & $1+($ stix $)$ & Mesangial & 3 & 1.7 \\
\hline 6 & Normal & 85 & Negative & Mesangial & 9 & - \\
\hline \multirow[t]{3}{*}{7} & 3-5 leukocytes & 20 & $1+($ stix $)$ & Mesangial & 9 & 23 \\
\hline & 15-20 erythrocytes & & & Interstitial & & \\
\hline & Haem granular casts & & & Fibrosis & & \\
\hline
\end{tabular}

* Creatinine clearance. $¥$ Total content PCA (mU/10 monocytes). $§$ Plasminogen activator (percent of maximum cpm released).

PCA in all of the active patients. Prolongation of the clotting time in a plasma deficient in a known factor indicated that the deficient factor was necessary for full PCA expression. The quantity of PCA associated with patients in group 2 (elevated PCA) was similar in plasmas genetically deficient in Factors XII, VIII, VII, $\mathrm{X}$, or $\mathrm{V}$ as compared with normal pooled plasma (Table VII). Although the data presented represent the results from one of the patients studied (patient 15), the results represent all of the active patients in that the procoagulant activity was dependent only on Factor II (prothrombin), fibrinogen, and calcium for its full activity. However, in plasma deficient in Factor II (prothrombin), no clot formation was seen. The addition of physiologic concentrations of purified prothrombin $(80 \mu \mathrm{g} / \mathrm{ml})$ to Factor II deficient plasma fully restored the capacity of this deficient plasma to undergo clot formation (Table VIII). Furthermore, both viable cells as well as cellular homogenates from monocytes from these patients, when added to isolated prothrombin and fibrinogen in the presence of $\mathrm{CaCl}_{2}$, initiated the formation of a fibrin clot. In contrast, when PBM from controls or patients in Group 1 and 3 were added to prothrombin and fibrinogen, no clot formation was observed.

To further demonstrate that this augmented spontaneous PCA had direct prothrombinase activity, cellular homogenates were incubated with ${ }^{125} \mathrm{I}$-prothrombin for $30 \mathrm{~min}$ at $37^{\circ} \mathrm{C}$ and the reaction was terminated by the addition of $1 \%$ SDS and $1 \%$ EDTA. After SDS-PAGE, the cleavage pattern was depicted by autoradiography. In Fig. 1, a single high molecular weight species of intact ${ }^{125} \mathrm{I}$-prothrombin was observed after incubation with buffer and calcium or with an aliquot of cellular homogenates from normal controls or patients from groups 1 and 3 . To determine percent cleavage of ${ }^{125} \mathrm{I}$-prothrombin, the gels were sliced and counted in a gamma counter. Cellular homogenates from patients in group 2, where high levels of PCA were found, yielded $>74 \%$ of the ${ }^{125}$ I-prothrombin cleaved, whereas $<1 \%$ cleavage was observed when cells from patients with base-line PCA were used. The PCA expressed from monocytes from patients in group 2 was not inhibited by antithrombin III in the presence of heparin, soybean trypsin inhibitor, trasylol, benzamidine, PMSF, or specific antibody to Factor $\mathrm{X}$, whereas $>75 \%$ inhibition of Factor $\mathrm{Xa}$ was observed in the presence of these protease inhibitors. Furthermore, whereas $10 \mathrm{mM}$ DFP was required to inhibit Factor Xa cleavage by prothrombin, as little as $2.0 \mathrm{mM}$ DFP inhibited the cellular prothrombinase (data not shown).

Monocyte plasminogen activator levels in patients with SLE. Plasminogen activator (PA), a neutral protease, is a monocyte product associated with monocyte activation. Ad-

Table V. Spontaneous Monocyte Procoagulant Activity from Patients in Group 2

\begin{tabular}{|c|c|c|c|c|c|c|}
\hline Patient no. & Microscopic urinalysis & Creatinine clearance§ & Urine protein & Renal pathology & $\mathrm{PCA}^{*}$ & PA \\
\hline & & & $g / 24 h$ & & & \\
\hline 8 & $10-12$ erythrocytes & 100 & 0.5 & FPGN & 1,000 & 0.3 \\
\hline 9 & $10-15$ erythrocytes & 90 & 1.8 & FPGN & 800 & - \\
\hline 10 & 4-8 erythrocytes & 90 & 0.5 & DPGN & 2,450 & 1.2 \\
\hline 11 & 5-10 erythrocytes & 100 & 0.2 & DPGN & 1,100 & 0 \\
\hline 12 & Erythrocytes, hgc & 34 & 7.0 & DPGN & 2,950 & 4.1 \\
\hline 13 & 5-10 erythrocytes, hgc & 111 & Negative & DPGN & 1,800 & - \\
\hline 14 & 4-6 erythrocytes, hgc & 25 & 6.6 & DPGN/RVT & 1,500 & 37.0 \\
\hline 15 & Normal & 92 & Negative & DPGN & 2,400 & 21.0 \\
\hline 16 & Normal & 100 & 1.4 & $\begin{array}{c}\text { Membranous GN } \\
++ \text { deposits }\end{array}$ & 7,000 & 1.0 \\
\hline
\end{tabular}

* Total content PCA (mU/10 moncytes). ‡ Plasminogen activator (percent of maximum cpm released). § Creatinine clearance (ml/min). hgc, haem granular casts. DPGN, diffuse proliferative glomerulonephritis. FPGN, focal proliferative glomerulonephritis. RVT, renal vein thrombosis. 
Table VI. Correlation of PCA

Determinations with Disease Activity

\begin{tabular}{lll}
\hline & \multicolumn{2}{l}{ PCA $^{*}$} \\
\cline { 2 - 3 } Patient no. & Active‡ & Inactive§ \\
\hline 10 & 2,450 & 15 \\
11 & 1,100 & 12 \\
13 & 1,800 & 8 \\
15 & 2,400 & 12 \\
\hline
\end{tabular}

* Total content PCA (mU/10 $10^{6}$ moncytes).

$\ddagger$ Activity defined as diffuse proliferative glomerulonephritis on renal biopsy.

$\S$ Inactivity defined by resolution of clinical renal disease if present, and extrarenal features.

ditionally, its action (fibrinolysis) is the opposite of the monocyte PCA. Cells from most of the patients in the study had monocyte PA determinations, and as can be seen, the PA showed no correlation with activity of SLE or PCA (Tables IV, V, and VII). In a few cases, however (patients 1,7 , and 22), an inverse relationship existed between monocyte PCA and PA suggesting that the production of these two proteases might be linked although in two other patients (patient 14 and 15) both monocyte PCA and PA were elevated.

\section{Discussion}

Renal involvement in SLE is one of the most significant factors in determining morbidity and mortality (2). Reports by Baldwin et al. (1) suggest that the renal pathology in patients with SLE correlates well with the prognosis. While investigators disagree concerning whether there is a prognostic advantage to the data provided by renal biopsy as compared with conventional laboratory assessment of renal function (21, 22), some authors have described significant numbers of patients with normal renal laboratory variables who had diffuse proliferative glomerulonephritis on renal biopsy $(23,24)$.

The results of this study demonstrate that the spontaneous expression of monocyte/macrophage PCA correlated with endocapillary proliferation in patients with glomerulonephritis and SLE. Furthermore, this correlation was superior to that observed with either lupus serology, serum complement levels, or laboratory indices of renal function. In the 24 patients studied with SLE, no correlation was observed between the extrarenal manifestations of SLE and monocyte PCA. Admittedly, since current renal pathology was not available in group 3 , one cannot draw firm conclusions in these patients. However, a striking correlation was observed between evidence of endocapillary proliferation, active renal lesions, and expression of PCA in the other patients. It is noteworthy that patient 15, who had no laboratory evidence of renal disease, and patients 10 and 11 , who had only minimal laboratory abnormalities, had diffuse proliferative glomerulonephritis with active lesions on biopsy and marked elevations in monocyte PCA. Similarly, patient 7, who presented with apparent acute onset of renal failure and an active urine sediment, and who was felt to have diffuse proliferative glomerulonephritis clinically, was found on biopsy to have a mesangial lesion with interstitial fibrosis and no elevation in monocyte PCA. In patient 16, a marked elevation in monocyte PCA was found, although renal biopsy only demonstrated a membranous lesion. The significance of this is unclear. This may represent a false positive, or the expression of PCA may have antedated the subsequent development of the diffuse proliferative lesion that was seen in this patient. In four of the patients who initially had marked elevations of monocyte PCA, a fall in PCA occurred with successful treatment, although repeat renal biopsy was not performed.

Activation of the coagulation system in SLE has been previously reported by a number of investigators. Kant et al. (25) reported on the high incidence of glomerular thrombi in biopsies from patients with SLE. They also suggested that the presence of fibrin without the third component of human complement in patients with circulating anticoagulants was evidence in favor of cell-mediated reactions as opposed to immune complex mediated disease. Hardin et al. (26) found elevated fibrinopeptide A levels in all patients with active SLE, and the increase occurred in proportion to the degree of activity of disease.

Cells of the monocyte/macrophage series play a central role in the immune and inflammatory response to a variety of agents $(15,27-29)$. The responses can result from either the direct interaction of the agents with the monocyte/macrophages or through the interactions of these cells with $T$ and $B$ lymphocytes and their products (15). Monocytes and macro-

Table VII. Spontaneous Expression of Monocyte PCA in Patients in Group 3

\begin{tabular}{|c|c|c|c|c|c|c|}
\hline Patient no. & Microscopic urinalysis & Creatinine clearance & Urine protein & Renal pathology & $\mathrm{PCA}^{*}$ & PAf \\
\hline & & $\mathrm{ml} / \min$ & $g / 24 h$ & & & \\
\hline 17 & Anuric & N.A. & N.A. & DPGN & 9 & - \\
\hline 18 & 5-8 erythrocytes & 80 & 5.2 & DPGN & 9 & 0.0 \\
\hline 19 & Normal & 96 & 1.8 & DPGN & 3 & 2.4 \\
\hline 20 & Granular casts & 80 & 1.7 & Unknown & 1 & 0.0 \\
\hline 21 & Granular casts & 120 & 0.8 & Unknown & 1 & - \\
\hline 22 & Normal & 100 & 0.25 & Unknown & 3 & 42.0 \\
\hline 23 & Normal & 90 & Negative & Unknown & 8 & 1.7 \\
\hline 24 & Normal & 130 & Negative & Unknown & 6 & - \\
\hline
\end{tabular}

* Total content PCA (mU/10 monocytes). $¥$ Plasminogen activator (percent of maximum cpm released). DPGN, diffuse proliferative glomerulonephritis. N.A., not available. 
Table VIII. Characterization of the PCA Associated with a Patient with Glomerulonephritis Associated with Systemic Lupus Erythematosus

\begin{tabular}{|c|c|c|c|c|c|c|c|c|}
\hline \multirow[b]{2}{*}{ Patient 15} & \multirow{2}{*}{$\begin{array}{l}\text { Normal human } \\
\text { plasma }\end{array}$} & \multicolumn{7}{|c|}{ Factor-deficient plasmas } \\
\hline & & XII & VIII & VII & $\mathbf{x}$ & $\mathbf{v}$ & II & $+\mathrm{II}^{*}$ \\
\hline Time $(s) \ddagger \S$ & 44 & 43 & 45 & 43 & 44 & 43 & $>120$ & 43 \\
\hline PCA (mU/10 $60^{6}$ mocytes) & 7,100 & 7,400 & 6,850 & 7,400 & 7,100 & 7,400 & $<1$ & 7,400 \\
\hline
\end{tabular}

* Prothrombin-deficient plasma to which $80 \mu \mathrm{g} / \mathrm{ml}$ purified prothrombin was added. $\ddagger 10^{5}$ monocytes assayed after disruption by freeze-thawing and sonication in either normal human citrated plasma or in factor-deficient plasma. §One-stage clotting times. Values represent the mean of three determinations.

phages have well recognized phagocytic functions and can be induced to secrete many biologically active products including a number of secretory enzymes in response to challenge. Activation of the coagulation system is a common feature in response to infection and is an important element in host defense as well as a necessary component of the delayed cutaneous hypersensitivity reaction (30). Monocyte/macrophages can be stimulated by LPS, antigens, viruses, and lipoproteins to express augmented PCA (31). The details of the cellular pathways by which this response can be invoked are not fully elucidated (32), and may depend on the particular stimulating agent. Investigations in some laboratories have suggested that monocytes may respond directly to LPS in the generation of PCA $(33,34)$. More recent evidence suggests a direct role for lymphocytes in the expression of PCA by monocytes in response to LPS and immune complexes (15, 35). Geczy and Hopper (36) have shown that a subpopulation of $\mathrm{T}$ cells produces a lymphokine resulting in the expression of PCA by adherent cells in response to antigen stimulation. Helin and Edgington (37) have shown that the allogeneic induction of PCA during a mixed lymphocyte reaction is $T$ cell-dependent, and have further shown that cyclosporine can abrogate this response (38).
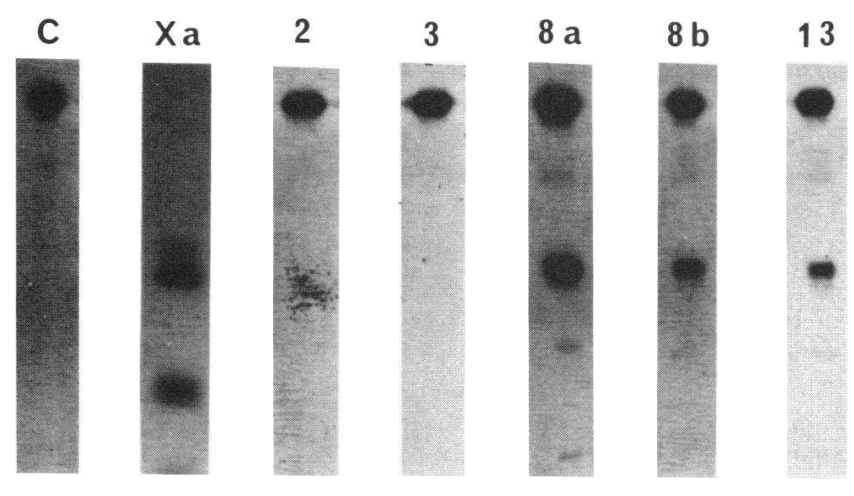

Figure 1. Cleavage of ${ }^{125} \mathrm{I}$-prothrombin by human Factor $\mathrm{X}_{\mathrm{a}}$ and human prothrombinase. $0.01 \mathrm{ml}$ of $100 \mathrm{nM}{ }^{125} \mathrm{I}$-prothrombin was incubated with $0.01 \mathrm{ml} \mathrm{CaCl} 2(25 \mathrm{mM})$ and $0.05 \mathrm{ml}$ of test sample for $30 \mathrm{~min}$ at $37^{\circ} \mathrm{C}$. SDS, B-mercaptoethanol, and EDTA were then added and the samples were applied to $10 \%$ SDS polyacrylamide slab gels. After electrophoresis, the gels were developed and counted for radioactivity. ${ }^{125} \mathrm{I}$-prothrombin was incubated with $10^{6}$ control cells (lane 1), with purified human Factor $\mathrm{Xa}(150 \mathrm{ng} / \mathrm{ml}$, final concentration) (lane 2), with $10^{6}$ cells isolated from patients 2 and 3 (lanes 3 and 4 , respectively), patient 8 (lanes 5 and 6 ) on two different days, and from patient 13 (lane 7).
Monocyte PCA could be an important mediator in disease activity by a number of mechanisms. It is conceivable that the induction of PCA could play a role in disease by direct activation of the coagulation system, which could result in regional microcirculatory disturbances in conjunction with fibrin formation. However, the failure to find thrombi and/or fibrin in all of the patients we have studied who expressed augmented PCA might mitigate against this possibility. Admittedly, detection of fibrin by immunofluorescent techniques is insensitive. However, studies of Kant and co-workers (25), who looked very carefully for glomerular thrombi, were able to show thrombi in only $50 \%$ of patients with SLE and proliferative glomerulonephritis (GN). Thus, our findings agree with other published data. Second, since it has recently been shown that thrombin is a potent chemoattractant for human monocytes, the production of prothrombinase may play a role in the development of the cellular infiltrate that occurs in the kidneys of patients with active disease, and thus contribute to the immunologic injury (39). It has been shown that the expression of monocyte PCA correlates directly with the delayed cutaneous hypersensitivity reaction, and thus, the prothrombinase may be a mechanism by which monocytes recruit appropriate effector cells after contact with foreign antigens. Additionally, as PCA is a serine protease, it could alter receptors on the surface of target cells, making them more susceptible to attack by other cellular systems. The fact that monocyte PA did not correlate with renal activity in this study strengthens the importance of PCA as a mediator in GN and further defines this molecule as a unique activity and not just a signal of macrophage activation.

\section{Acknowledgments}

This work was supported by grants from the Wellesley Hospital Research Foundation, the Kidney Foundation of Canada, and Grant MA 6787 from the Medical Research Council of Canada.

\section{References}

1. Baldwin, D. S., M. C. Gluck, J. Lowenstein, and G. Gallo. 1977. Lupus nephritis: clinical course as related to morphologic form and their transitions. Am. J. Med. 62:12-30.

2. Karsh, J., J. H. Klipper, J. E. Ballo, and J. L. Decker. 1979. Mortality in lupus nephritis. Arthritis Rheum. 22:764-768.

3. Abrass, C. K., K. M. Nies, J. S. Louie, W. A. Border, and R. J. Glassock. 1980. Correlation and predictive accuracy of circulating immune complexes with disease activity in patients with systemic lupus erythematosus. Arthritis Rheum. 23:273-282.

4. Lloyd, W., and P. H. Schur. 1981. Immune complexes, comple- 
ment and anti DNA in exacerbations of systemic lupus erythematosus. Medicine (Baltimore). 60:208-217.

5. Jarrett, M. P., L. B. Sablay, L. Walter, P. Barland, and A. I. Grayzel. 1981. The effect of continuous normalization of serum haemolytic complement on the course of lupus nephritis. Am. J. Med. 70:1067-1072.

6. Hunsicker, L. G., T. P. Shearer, S. B. Plattner, and D. Weisenburger. 1979. The role of monocytes in serum sickness nephritis. $J$. Exp. Med. 150:413-425.

7. Striker, G. E., M. Mannick, and M. Y. Tung. 1979. Role of marrow derived monocytes and mesangial cells in removal of immune complexes from renal glomeruli. J. Exp. Med. 149:127-136.

8. Holdsworth, S. R., T. J. Neale, and C. B. Wilson. 1981. Abrogation of macrophage dependent injury in experimental glomerulonephritis in the rabbit. Use of an antimacrophage serum. J. Clin. Invest. 68:686-698.

9. Holsworth, S. W., N. M. Thomson, E. F. Glasgow, and R. C. Atkins. 1979. The effect of defibrination on macrophage participation in rabbit nephrotoxic nephritis: studies using glomerular culture and electron microscopy. Clin. Exp. Immunol. 37:38-43.

10. Thomson, N. M., I. J. Simpson, and D. K. Peters. 1975. A quantitative evaluation of anticoagulants in experimental nephrotoxic nephritis. Clin. Exp. Immunol. 19:301-312.

11. Kincaid-Smith, P. 1972. The treatment of chronic mesangiocapillary glomerulonephritis with impaired renal function. Med. $J$. Aust. 2:587-592.

12. Pollak, V. E., H. I. Glueck, M. A. Weiss, A. Lebron-Berges, and M. A. Miller. 1982. Defibrination with ancrod in glomerulonephritis: effects on clinical and histologic findings and on blood coagulation. Am. J. Nephrol. 2:195-207.

13. Bowie, E. J. W., J. H. Thompson, Jr., and C. A. Pascuzzi. 1963. Thrombosis in S.L.E. despite circulating anti-coagulants. J. Lab. Clin. Med. 62:416-430.

14. Rickles, F. R., J. A. Hardin, F. A. Pitlick, L. W. Hoyer, and M. E. Conrad. 1973. Tissue factor activity in lymphocyte cultures from normal individuals and patients with hemophilia. Am. J. Clin. Invest. 52:1427-1433.

15. Levy, G. A., and T. S. Edgington. 1980. Lymphocyte cooperation is required for amplification of macrophage procoagulant activity. $J$. Exp. Med. 151:1232-1234.

16. Sunsmo, J. S., and D. S. Fair. 1983. Relationships among complement, kinin, coagulation, and fibrinolytic systems. In Springer Seminars in Immunopathology. H. Muller-Eberhard, editor. Springer Publishing Co., Inc., New York. 6:231-258.

17. McCluskey, R. T. 1975. Lupus nephritis. In Kidney Pathology Decentennial 1966-1975. S. C. Sommers, editor. Appleton-CenturyCrofts, East Norwalk, CT. 435-460.

18. Schwartz, B. S., G. A. Levy, D. S. Fair, and T. S. Edgington. 1982. Murine lymphoid procoagulant activity induced by bacterial lipopolysaccharide and immune complexes is a monocyte prothrombinase. J. Exp. Med. 155:1464-1479.

19. Laemmli, U. K. 1970. Cleavage of structural proteins during the assembly of the head of bacteriophage T4. Nature (Lond.). 27:680681.

20. Deutsch, H., and D. Mertz. 1970. Isolation and purification of plasminogen. Nature (Lond.). 170:1095-1096.

21. Whiting-O'Keefe, Q., P. J. Riccardi, J. E. Henke, M. A. Shearn, J. Hopper, and W. V. Epstein. 1982. Recognition of information in renal biopsies of patients with lupus nephritis. Ann. Intern. Med. 96: 723-727.
22. Fries, J. F., J. Porta, and M. H. Liang. 1978. Marginal benefit of renal biopsy in systemic lupus erythematosus. Arch. Intern. Med. 138:1386-1389.

23. Mahajan, S. K., N. G. Ordonez, P. J. Feitelson, V. S. Lim, B. H. Spargo, and A. I. Katz. 1977. Lupus nephropathy without clinical renal involvement. Medicine (Baltimore). 56Z:493-501.

24. Hollcraft, R. M., E. L. Dubois, G. D. Lundberg, M. B. Chandor, S. B. Gilbert, F. P. Quismorio, B. H. Barbour, and G. J. Friou. 1976. Renal damage in systemic lupus erythematosus with normal renal function. J. Rheumatol. 3:251-261.

25. Kant, K. S., V. E. Pollak, M. A. Weiss, H. I. Glueck, M. A. Miller, and E. V. Hess. 1981. Glomerular thrombosis in Systemic Lupus Erythematosus: prevalance and significance. Medicine (Baltimore). 60:71-86.

26. Hardin, J. A., M. Cronlund, E. Haber, and K. J. Bloch. 1978. Activation of blood clotting in patients with systemic lupus erythematosus. Relation to disease activity. Am. J. Med. 65:430-435.

27. Rothberger, H., T. S. Zimmerman, H. L. Spiegelberg, and J. H. Vaughan. 1977. Leukocyte procoagulant activity. Enhancement of production in vitro by IgG and antigen antibody complexes. J. Clin. Invest. 59:549-554.

28. Garg, S. K., and J. Niemetz. 1973. Tissue factor activity of normal and leukemic cells. Blood. 42:729-735.

29. Levy, G. A., B. S. Schwartz, L. K. Curtiss, and T. S. Edgington. 1981. Plasma lipoprotein induction and suppression of the generation of cellular procoagulant activity in vitro. Requirements for cellular collaboration. J. Clin. Invest. 67:1614-1622.

30. Colvin, R. B., M. W. Mossesson, and H. F. Dvorak. 1979. Delayed type hypersensitivity skin reactions in congenital afibrinogenemia lack fibrin deposition and induration. J. Clin. Invest. 63:13021306.

31. Levy, G. A., H. Helin, and T. S. Edgington. 1984. The pathobiology of viral hepatitis and immunologic activation of the coagulation protease network. Semin. Liver Dis. 4:965-975.

32. Edgington, T. S., B. S. Schwartz, G. A. Levy, and D. S. Fair. 1982. Unidirectional T lymphocyte Induction of Monocyte Procoagulant Molecules. 1980. In Immunopathology: VIII International Symposium. Academic Press, Inc., New York. 25-55.

33. Edwards, R. L., and F. R. Rickles. 1978. Lymphocyte requirement for monocyte tissue factor generation. Blood. 52(Suppl.): 180 .

34. Edwards, R. L., and F. R. Rickles. 1980. The role of human $\mathrm{T}$ cells and $\mathrm{T}$ cell products for monocyte tissue factor generation. $J$. Immunol. 125:606-609.

35. Schwartz, B. S., and T. S. Edgington. 1981. Immune complex induced human monocyte procoagulant activity. A rapid unidirectional pathway. J. Exp. Med. 154:892-898.

36. Geczy, C. L., and K. E. Hopper. 1981. A mechanism of migration inhibition in delayed-type hypersensitivity reactions. II. Lymphokines promote procoagulant activity of macrophages in-vitro. J. Immunol. 126:1059-1065.

37. Helin, H. J., and T. S. Edgington. 1983. Allogeneic induction of the human $T$ cell instructed monocyte procoagulant response is rapid and elicited by HLA-DR. J. Exp. Med. 158:962-970.

38. Helin, H. J., and T. S. Edgington. 1983. Cyclosporin A regulates monocyte/macrophage effector functions by affecting instructor $T$ cells: inhibition of monocyte procoagulant response to allogeneic stimulation. J. Immunol. 132:1074-1076.

39. Bar-Shavit, R., A. Kahn, and G. D. Wilner. 1983. Monocyte Chemotaxis: stimulation by specific exosite region in thrombin. Science (Wash. DC). 220:728-731. 